IJMS 2016 vol. 4 (1): 67-73

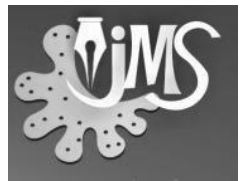

\title{
Influence of Effective Microorganisms on Growth Performances of Broiler Chicken under Local Conditions
}

\author{
Jayathilaka BR ${ }^{1}$, Nayananjalie WAD ${ }^{1}$, Adikari $\mathrm{AMJB}^{1}$ and Samaraweera BWNJ² \\ ${ }^{1}$ Department of Animal and Food Sciences, Faculty of Agriculture, Rajarata University of Sri Lanka, \\ Puliyankulama, Anuradhapura, Sri Lanka \\ ${ }^{2}$ Livestock Experiment Unit, Faculty of Agriculture, Rajarata University of Sri Lanka, Puliyankulama, \\ Anuradhapura, Sri Lanka
}

\begin{abstract}
The study was conducted to assess the effects of Effective Microorganisms (EM) as an additive to drinking water on growth performance of broiler chicken under local conditions. Hundred and ninety eight, day-old chicks were randomly allocated into two treatments, in a Complete Randomized Design (CRD) with three replicates of 33 birds per each. One group was fed with EM in $10 \mathrm{~mL} E M / L$ concentration level with drinking water and other group was considered as the control. Body weights of birds were measured at day 1, 10, 26 and 42 and feed intakes were measured weekly. Weight gain and feed conversion ratio (FCR) were calculated for the starter, finisher and total study period separately. At the age of 42 days, ten birds were randomly selected from each pen and scarified. Observed data were analyzed using the T-test procedure in 'SAS'. Growth performance and FCR in starter period were significantly different $(p<0.05)$ between EM treated and control group. The groups treated with EM showed significantly higher body weight, feed intake and FCR compared to control group during starter period $(p<0.05)$. However, in the finisher period, EM did not significantly affect growth or FCR of birds ( $p>0.05)$. Total feed intake was significantly higher in EM treated birds than control group $(p<0.05)$. There were no significant difference observed in FCR, carcass yield and dressing percentage between $10 \mathrm{~mL}$ EM/L EM treated birds and control ( $p>0.05)$. In conclusion, EM positively affected the initial growth phase of broilers under local conditions though there is no significant influence on their latter part of growth.
\end{abstract}

KEYWORDS: Broilers, drinking water, effective microorganisms, growth performances

Corresponding author: B. R. Jayathilaka, email: bhathiyabrj@gmail.com 


\section{INTRODUCTION}

Chicken meat is relatively cheap compared to other animal products thus made it most consumed animal protein sources in the average Sri Lankan diets. However, the demand is mainly dependent on consumers' perceptions and meat quality. Today, meat quality plays a greater significance on public attention and demand is based on high in lean content, low in fat, cholesterol and calories. Further, food safety and hygiene, especially the presence of pathogenic microorganisms and chemical residues crucially affect the consumer preference. Therefore, probiotics or microbial preparations are used to improve production performance and product quality of broilers. The concept of effective microorganisms (EM) which consist of mixed cultures of beneficial and naturally-occurring microorganisms contain selected species including predominant populations of lactic acid bacteria, yeasts, small number of photosynthetic bacteria, actinomycetes and other types of beneficial organisms is emerging research topic in Sri Lanka (EMRO, 2010).

Effective microorganisms were developed by Professor Teruo Higa of the University of Ryukyus, Okinawa, Japan in 1980s (Higa, 1994). It is a liquid at $\mathrm{pH}$ of 3.5 that is formed at high pressures by the interaction of a diverse group of naturally occurring, aerobic and facultative anaerobic microorganisms (Guim et al., 1998). Effective microorganisms are widely used in the livestock sector to improve and promote the health condition and growth performance, control the disease and odor problems and as an agent of waste treatment in poultry production. When EM is added to the feed and water, the beneficial microorganisms tend to improve the gut flora of the birds. It facilitates efficient digestion and boosts the immune system. Thereby, it increases growth rate, egg production and reproductive performance and improve the health conditions of chicken (EMRO, 2010). It is also helping to reduce the feed costs and increase the productivity of poultry industry. One of the most valuable contributions of EM to the livestock industry is its deodorizing effect within confined facilities for poultry operations. It is used in rearing sheds as a spray to suppress disease causing microorganisms, eliminate and control the ammonia produced from droppings and it helps to improve quality of the air (EMRO, 2010). Effective microorganisms eliminate odors by dominating the microbial ecology with organisms that exploit a fermentative pathway and therefore do not produce odorous gases (Yongzhen and Weijiong, 1994).

Effective microorganisms are a developing technology that may support the profitability and safety of poultry production and offer meaningful alternatives for natural and organic production in the world. Under the Sri Lankan condition, EM technology is rarely used in the poultry sector due to the lack of knowledge on beneficial effects of these organisms. Therefore, this study was conducted to investigate the effects of EM incorporated drinking water on growth performances and dressing percentage of broilers under dry zone farm conditions in Sri Lanka.

\section{METHODOLOGY}

\section{Animal Experiment}

The animal experiment was conducted at Livestock Experiment Unit, Faculty of Agriculture, Rajarata University of Sri Lanka, Puliyankulama. One hundred and ninetyeight, day-old broiler chicks were obtained from a commercial hatchery. These chicks were randomly assigned to EM treatment and control with three replicates. Each replicate consisted of 33 birds. EM treatment was prepared by mixing hard drinking water with EM solution at the concentration of $10 \mathrm{~mL}$ EM/L. Birds were fed with commercial starter and finisher feeds and proximate composition of the feed as per feed manufacturer is presented in Table 1. 
Table 1. Nutritional composition of commercial feeds

\begin{tabular}{|l|l|l|}
\hline Nutrients & Starter & Finisher \\
\hline Protein (\%) & 22 & 20 \\
Fat (\%) & 6 & 7 \\
Ash (\%) & 7 & 7.5 \\
Fiber (\%) & 4.5 & 4.5 \\
Calcium (\%) & $9.5-1.2$ & $0.9-1.2$ \\
Phosphorous (\%) & $0.7-1$ & $0.7-1$ \\
Metabolizable Energy (kcal / kg) & 3000 & 3100 \\
\hline
\end{tabular}

(Source: CIC Agri-business, 2014)

Before the arrival of the chicks, rooms, brooder guards, feeders and waterers were thoroughly cleaned. Broiler chicks were divided into two groups and each group included 99 chicks. They were randomly distributed into two brooders and reared under good hygienic conditions. Chicks were spent ten days of brooding period and 100 W electric bulbs were used to provide the initial heating and lighting. All chicks were provided with Vitamin E, chick-tonic and glucose solution with drinking water to reduce the stress at the time of arrival. All birds were vaccinated against infectious brusal disease (IBD) and New castle disease in the first week of their life. All birds were provided with feed and water ad libitum twice a day; in the morning and evening. After $21 \mathrm{~d}$ of feeding, the starter ration was gradually switched to the finisher ration, which was fed for an additional 14 days. Water was provided with mentioned specific ration of EM solution. All other general management practices were followed until the birds were slaughtered.

Ten birds from each replicate were slaughtered at the end of the experiment. Anti-mortem inspections were done by visual observations. Birds were starved for about 20 - 24 hours and they were weighed before slaughter.

\section{Data Collection, Sampling and Calculations}

Given feed and remained feed were measured weekly throughout the study period. Average body weight of bird was measured at day 1, 10, 26 and 42. Feed intakes, feed conversion ratio
(FCR) and dressing percentages were calculated.

Data were analyzed using the T-test procedure in Statistical Software for Data Analysis (ver. 9.0, SAS, 1996) to evaluate the effect of EM on broilers and statistical significance was declared at $\mathrm{p}<0.05$.

\section{RESULTS AND DISCUSSION}

The effects of supplementation of EM in drinking water on growth performances and dressing percentage of broilers are summarized in Table 2.

Body weight was significantly different $(p<0.05)$ between EM treated group and control at $\mathrm{d} 10$ and body weight of EM treated group was higher than the control (Table 2). However, there were no any significant differences ( $>00.05$ ) between control and EM treated groups with regard to body weight at day 26 and day 42 ( $>00.05$ ). It was found that, body weight gain was greater in birds treated with EM than those consumed water free of EM at initial stage. Such increase may be attributed to enhancement of feed utilization efficiency as reflected by improved in feed conversion ratio observed in the study. These findings confirmed to those of Lesson and Summers (1997), Hussein and Ashry (1991) and Hussain et al., (1996) who showed that live body weight was significantly greater in all groups treated with different types of probiotics compared with the control group. The 
best weight gain in broiler treated with specific type of probiotics could be related to better digestibility of crude protein and crude fiber (Kierhan, 2010).

Table 2. The comparison of performance characteristics of broiler chickens in EM treated and control group

\begin{tabular}{|c|c|c|}
\hline Parameter & Treated with EM & Control \\
\hline \multicolumn{3}{|l|}{ Body weight (g/bird) } \\
\hline $\mathrm{d} 1$ & $40 \pm 0.33$ & $40.3 \pm 0.33$ \\
\hline $\mathrm{d} 10$ & $245 \pm 4^{b}$ & $222 \pm 4^{\mathrm{a}}$ \\
\hline $\mathrm{d} 26$ & $1176.70 \pm 33$ & $1267 \pm 24$ \\
\hline \multicolumn{3}{|l|}{ Feed intake(g/bird) } \\
\hline $\mathrm{d} 1-\mathrm{d} 42$ & $4283 \pm 2^{b}$ & $4195 \pm 1^{\mathrm{a}}$ \\
\hline period $1-\mathrm{d} 21$ & $1535 \pm 2^{b}$ & $1447 \pm 1^{\mathrm{a}}$ \\
\hline period $22-\mathrm{d} 42$ & $2748.2 \pm 0.29$ & $2748 \pm 0.11$ \\
\hline \multicolumn{3}{|l|}{ Feed conversion ratio } \\
\hline $\mathrm{d} 1-\mathrm{d} 42$ & $1.79 \pm 0.05$ & $1.72 \pm 0.08$ \\
\hline d $1-$ d 21 & $1.32 \pm 0.04^{b}$ & $1.14 \pm 0.02^{\mathrm{a}}$ \\
\hline $\mathrm{d} 22-\mathrm{d} 42$ & $1.14 \pm 0.03$ & $1.13 \pm 0.05$ \\
\hline \multicolumn{3}{|l|}{ Dressing percentage } \\
\hline Live weight (g/bird) & $2405 \pm 63$ & $2447 \pm 104$ \\
\hline Carcass weight (g/bird) & $1968 \pm 39$ & $1965 \pm 103$ \\
\hline Dressing percentage (\%) & $81.88 \pm 1.26$ & $80.23 \pm 0.84$ \\
\hline
\end{tabular}

a,b means with different superscripts within the same row are significantly different $(\mathrm{p}<0.05)$

Body weight was significantly different $(p<0.05)$ between EM treated group and control at $\mathrm{d} 10$ and body weight of EM treated group was higher than the control (Table 2). However, there were no any significant differences ( $>0.05$ ) between control and EM treated groups with regard to body weight at day 26 and day 42 ( $>00.05)$. It was found that, body weight gain was greater in birds treated with EM than those consumed water free of EM at initial stage. Such increase may be attributed to enhancement of feed utilization efficiency as reflected by improved in feed conversion ratio observed in the study. These findings confirmed to those of Lesson and Summers (1997), Hussein and Ashry (1991) and Hussain et al., (1996) who showed that live body weight was significantly greater in all groups treated with different types of probiotics compared with the control group. The best weight gain in broiler treated with specific type of probiotics could be related to better digestibility of crude protein and crude fiber (Kierhan, 2010).

The results clearly show that, feed intake of birds in the EM treated group was significantly higher $(\mathrm{p}<0.05)$ than the control group during day 1- day 21 (Table 2). However, latter part of the experiment, feed intake of birds did not show any significant difference between EM treated and control groups ( $>>0.05)$. Further, total feed intake of EM treated group was significantly higher $(p<0.05)$ than control group. High feed intake observed in the present study may due to the improved digestion in broiler chickens and effect may be more significant during early growth stages of birds.

The result are in agreement with Simeamelak et al.,(2012) who showed that EM supplementary 
administration of drinking water improved growth performance of Rhode Island Red (RIR) chicks. It is proposed that EM may act in the intestinal tract of the birds by maintaining a beneficial microbial population in the alimentary tract (Fuller, 1989), increasing nutrient utilization through improved intestinal health resulting in greater intestinal enzyme activities and nutrient availability (Nahashon et al., 1994), altering bacterial metabolism (Cole et al., 1987) and competing with pathogenic micro-flora in the digestive tract (Wood and Abuchar, 1998).

Feed conversion ratio (FCR) of birds in starter period was significantly higher $(\mathrm{p}<0.05)$ in EM treated group compared to the control group. However, FCR of birds in finisher period and total study period did not significantly differ $(p>0.05)$ between two groups. Therefore, it appears that EM has little effect on FCR as both groups have similar FCR except during the early periods of their development. Feed conversion ratio as affected by probiotics is the subject of controversy. Similar to the present findings, several previous works suggested that supplementation of probiotics does not influence feed conversion ratio significantly or no such effect on FCR (Samanta and Biswas, 1995; Gohain and Sapcota, 1998; Ergun et al., 2000; Panda et al., 2000; Ahmad, 2004; Mohit et al., 2007).

Furthermore, carcass weights of birds between control and EM treated groups were not significantly different $(\mathrm{p}>0.05)$. Though there was no any difference in dressing percentage between control and treated group, FCR was higher in $10 \mathrm{~mL} \mathrm{EM} / \mathrm{L}$ EM treated group than control group. Similarly some studies showed that supplementation of probiotics had no effect on the performance of broiler chicks (ZuAnon et al., 1998; Patidar and Prajapati, 1999; Ergun et al., 2000; Kumprechtova et al., 2000). On the other hand, EM fed birds had significantly higher weight gain and lower FCR than control groups (Jagdish and Sen, 1993; Alvarez et al., 1994; Safalaoh, 2006). EM supplementation had little effect on growth parameters such as weight gain, mortality and FCR. According to previous studies, improved body weight gain is reflected in carcass yield in which, relatively higher values were observed in EM treated birds than control group (Bozkurt et al., 2009). The growth promoting effect of probiotics (particularly Saccharomyces cerevisiae) is attributed to the growth improvement, due to the fact that it is a naturally rich source of protein, minerals and Vitamin B-complex (Shareef and Al-Dabbagh, 2009). The greater physiological activity in animals and better feed conversion efficiencies may be attributed for improved growth performance for broilers and use of probiotics has also been shown to improve protein efficiency ratios and nitrogen utilization in broilers (Safalaoh, 2006).

Observed results in the present study were somewhat different compared to already published studies conducted in the other countries. This may be due to variation in environmental conditions since environment has an impact on performances of broilers. In this research, single ratio of EM solution was only used, although it is better to use several deferent ratios to find out the most suitable EM ratio which gives higher effectiveness. EM was provided with drinking water in the present study and EM which is providing as feed additives is most important factor to find the effectiveness of EM, and also EM solutions can be spread on litter to control the odour. In this, probiotic benefits of EM did not measure which is used to control diseases. Therefore, further research is needed to justify the economic benefits, feed conversion efficiency, growth performance, malodour and disease control in different localities in Sri Lanka using different EM dosage levels for longer periods. However, this study was conducted with limited number of chicks. It needs to be strengthened by similar works that involve large number of animals for prolonged period of time. Therefore, to arrive at better understanding and conclusion on the role of EM and its future utilization in poultry farming the above mentioned points need to be 
addressed in future researches to achieve more accurate conclusions for its future application in poultry farms.

\section{CONCLUSION}

Effective microorganism supplemented with drinking water has no effect on carcass yield and dressing percentage of broiler chicken. However, EM promotes the early growth performances in broiler chicken reared under dry zone condition.

\section{REFERENCES}

AHMAD I. Effect of probiotic (protexin) on the growth of broilers with special reference to the small intestinal crypt cells proliferation. M. Phil Thesis, Centre of Biotechnology, University of Peshawar. 2004.

ALVAREZ LC, BARRERA EM \& GONZALEZ EA. Evaluation of growth promoters for broiler chickens. Veterinaria Mexico. 1994; 25: 141-144.

BOZKURT M, KUCUKYILMAZ K, CATH AU \& CINAR $M$. The effect of single or combined dietary supplementation of prebiotics, organic acid and probiotics on performance and slaughter characteristics of broilers. South African Journal of Animal Science. 2009; 39(3):197-205. Accessed on November 08, 2015 from: http://www.sasas-co.za/sajas.asp

COLE CB, FULLER R \& NEWPORT MJ. The effect of diluted yoghurt on the gut microbiology and growth of piglets. Food Microbiology. 1987; 4(1): 83-85.

EM RESEARCH ORGANIZATION (EMRO). Working with EM technology for sustainable environment. 2010; Accessed on November 06, 2015 from: http://www.emsustains.co.uk
ERGUN A, YALCIN S \& SACAKLI P. The usage of probiotic and zinc bacitracin in broiler rations. Ankara Universities Veteriner Facultesi Dergisi. 2000; 47:271-280.

FULLER R. Probiotics in man and animals. Journal of App. Bacteriol. 1989; 66(5): 365-378.

GOHAIN AK, \& SAPCOTA D. Effect of probiotic feeding on the performance of broilers. Indian Journal of Poultry Science. 1998; 33:101105.

GUIM A, ANDRADE P, ITURRLNOSCHOCKEN RP \& MALHEIROS EB. Aerobic stability of wilted grass silages (Pennisetum purpureum, Schum) treated with microbial inoculants. Journal of Animal Science (English Version), Federal University of Vicosa, Sao Paulo, Brazil. 1998.

HIGA T. Effective Microorganisms - A holistic technology for humankind. Department of Horticulture, University of Ryukyus, Okinawa, Japan. 1994; Retrieved on November 10, 2015 from: http://www.infrc.org.jp

HUSSAIN T, AHMAD R, GILANI G \& HIGA T. Applied EM technology. Nature Farming Research Centre, University of Agriculture Faisalabad, Pakistan. 1996.

HUSSEIN HH \& EI-ASHRY MA. Some studies on the beneficial effect of Lactobacillus concentrate supplementation on broiler performance. Egyptian Journal of Animal Reproduction. 1991; 28(1):85-91.

JAGDISH P \& SEN AK. Effect of different growth promoters on the performance of broilers. Poultry Advisory. 1993; 26: 49-51.

KIERHAN JA. Histological and histochemical methods theory and practice. Scion publishing Ltd., London, UK, 2010; 281-286.

KUMPRECHTOVA D, ZOBAC P \& KUMPRECHT I. The effect of Sacchromyces 
cervisiae SC47 on chicken broiler performance and nitrogen output. Czech Journal of Poultry Science. 2000; 45: 169-177.

LEESON S \& SUMMERS JD. Commercial poultry nutrition. University books, Guelph, Ontario. 1997; 210-211.

MOHIT AH, HOSSEINI SA, LOTFOLLAHIAN H \& SHARIATMADARI F. Effects of probiotics, yeast, vitamin $\mathrm{E}$ and vitamin $C$ supplements on performance and immune response of laying during high environmental temperature. International Journal of Poultry Science. 2007; 6: 895-900.

NAHASHON SN, NAKAUE HS \& MIROSH LW. Growth variables and nutrient retention in single comb White Leghorn laying pullets fed diets supplemented with direct-fed microbials. Poultry Science. 1994; 73(11): 1699-1711.

PANDA AK, REDDY MR, RAO SVR, RAJU MVLN \& PRAHARAJ NK. Growth, carcass characteristics, immuno competence and response to Escherichia coli of broilers fed diets with various levels of probiotic. Archive fur Geflugelikunde. 2000; 64:152-156.

PATIDARSK, \& PRAJAPATI JB. Effect of feeding Lactobacilli on serum antibody titer and faecal microflora in chicks. Microbiologic Aliments Nutrition. 1999; 17: 145-154.

SAFALAOH ACL. Body weight gain, dressing percentage, abdominal fat and serum cholesterol of broilers supplemented with a microbial preparation. African Journal of Food, Agriculture and Nutrition Development. 2006; 6: 1-10.

SAMANTA M \& BISWAS P. Effect of feeding poultry probiotic and lactic acid on the performance of broiler. International Journal of Poultry Science. 1995; 30:145-147.

SHAREEF AM \& AL-DABBAGH ASA. Effect of probiotic (Saccharomyces cerevisiae) on broiler chicks. Iraqi Journal of Veterinary Sciences. 2009; 23-29. Retrieved on November 08, 2015 from: http://www.vetmedmosul.org/ijvs

SIMEAMELAK M, SOLOMON D \& TAYE T. Evaluation of effective microorganisms on production performance of Rhode Island Red chicks. GJSFR (D): AgriVet Science. 2012; 12(10): 23-29.

STATISTICAL ANALYSES SYSTEM (SAS). Users Guide Statistics, SAS Institute Inc. Cary, North Carolina, USA. 2002.

WOOD MT \& ABUCHAR D. Sustainable community development. 1998; Retrieved on March 20, 2016 from: http://www.emtrading.com/scd/useempoultry.p df

YONGZHEN N \& WAIJIONG L. Report on the deodorizing effect of effective microorganisms (EM) in poultry production. Beijing, China. 1994.

ZUANON JA, FONSECA S, ROSTAGNO HS, ALMEIDA M \& SILVA M. Effects of growth promoters on broiler chicken performance. Revista Brasileira de Zootecnia. 1998; 27: 9991005. 